\title{
Perspective Challenge to Implement an Adaptive Port Planning (APP): Taking Casablanca Port as an Example
}

\author{
Mohamed Azizi \\ Department of Communication, Transport \& Management \\ Shanghai Maritime University, Shanghai, China \\ Tel: 86-187-2121-2270Ｅ-mail: med.smu@gmail.com
}

Received: April 23, 2014 Accepted: June 3, 2014 Published: August 24, 2014

doi:10.5296/bms.v5i2.6204 URL: http://dx.doi.org/10.5296/bms.v5i2.6204

\begin{abstract}
The study have proposed Adaptive Port Planning (APP) to be implemented in Casablanca Port according to regulate manner operation with a framework, an approach that bridges the gaps in the traditional practices of port planning by incorporating uncertainty and flexibility considerations. It provides a framework for the planner to generate plausible alternatives in the context of this planning objectives and definition of success; identify critical uncertainties (vulnerabilities and opportunities); and then, to explore, value, and incorporate flexibilities for handling these uncertainties. Then, actions can be taken either in the planning stage, or actions can be prepared in advance, and taken as events occur. Next, the planner evaluates the alternatives and makes a choice; the value of flexibility is included in his evaluation. During the implementation phase, actions are taken in response to triggers from a monitoring system set up for the selected alternative (which monitors the external environment for new developments and alerts planners of the need to modify or reassess the plan).
\end{abstract}

Keywords: Port planning, Risk, Casablanca, Port capacity 


\section{Introduction}

Ports as risky businesses: In recent years there has been an exclusive combination of a systematic change addressed by globalization, acquiring new technology and growing the environmental awareness in combination with a series of seismic shocks to the global economic system (Van der Horst and De Langen, 2008). This has associations on the way countries live and make internal resources. So, these impacts blow a relevant view to the future to develop an infrastructure of country, a country as Morocco is moving fast enough to avoid local problems according to international infrastructure progress. If not, what Morocco should do to keep up a port permanent economic progress? In this dissertation, will address issues specifically on Morocco's Casablanca Port Infrastructure.

Basic services and facilities to provide excellent services to local firms require to pay relevant attention, such as infrastructure, transport, electricity, telecommunications, water, as well as energy. Casablanca Port infrastructure is a major issue according to the permanent trade and international goods flow, offering services to each ship and also cargos. In the past years from 1906, Casablanca port has been growing from its special location and development area. At present there are an international platform on logistics and production mechanisms (Pallis et al., 2008), local economics have movement from port industry, which require better infrastructure conditions to interact with their community as well as international group port (Wang et al., 2004), countries worldwide have permanent intertwined interest, those interests are not only related to transport and trade flow, but also financial issues, which this study will state on the following information that the international investment are sensitive issue to develop countries production or operation areas. (Jacobs et al., 2010; Blyde and Molina, D., 2013) states that today, the port regionalization system operation network are needed to maximize local economics building supply chain platform to have a stable competition.

A cause of this has been a major aspect on internal information with an aim to provide progresses in containerization platform. There are several issues to include on the platform to maximize containerization improvement efficiency as following:

a. Promotion

b. Leading to network efficient

c. Safety delivery

d. Monitoring the platform cost

Above as a phenomenon, which are needed to be measure on network and flow (Notteboom, 2004). Casablanca port production is a base to minimize process cost (transportation) and increase commercial and cargo performance looking to be a global port and integrated operation platform (S. Rick Fernandez, 2013).

\subsection{Needed to Improve Casablanca Infrastructure Port Platform}

Any country in the world request to develop an improvement on Infrastructure as Port, Roads, Railways, Buildings, as so on...), so, these need support from investment to contribute on 
Casablanca Port physical resources in the face of the modernization, the study will illustrate the sufferance and negligence that Casablanca Port have according the actual infrastructure conditions.

Issues to focus on development:

i. Facilities indoors

ii. Road access

iii. $\quad$ Port capacity (congestion in existing ports)

iv. Expansion

v. Other...

It $\mathrm{Can}$ be seen that info-technology have led new concept of logistics, where ports have to draft a potential infrastructure network to be competitive and acceptable on the international port network. Logistics concepts require a different port insight or terminal layout according to the update multimodal infrastructure. A growing interest in network and organization platform also requires innovative ports performance, as mention above, this entire structure request an extension on the part of the relevant assets, and internal or external investment would maximize port efficiency (Muriello and Jiji, 2004).

There are some important reason to be competitive as Casablanca port has the advantage on the geographical location, the potential logistics network, potential cargo efficiency, port facilities and port of multiple services. In order to exploit the potential of the convergence of the global economy and competitive market, and strengthen the position of a port under the changed requirements, and improve whole port sector efficiency, there is a need to build a platform capacity through investment in infrastructure as a mandatory request. Many ports in the worldwide are keeping updated infrastructure and the investment is the major challenge to reach a modern port as mentioned by (Marshall, R. (2001). As (Haddad et al. 2010) mention: "It's request enough infrastructure to provide acceptable levels of service while additional capacity is required to attract future progress." In the words of Chief Strategy Officer of Maersk Line Terminal (Yang, Shen, 2013) "Today, having the ability and the right aptitude is essential to the growth and success of the ports in the long term. Ensuring that the nautical infrastructure, operational design cranes and match the specifications of future ships is essential for the ports to get ahead in the progress."

\subsubsection{Risky Investments}

Worldwide ports industries are currently according to the internal or operation high cost as well as poor customer services, are needed to be under restrictions to be characterized in an operation and organizing environments platform, this require a new global operation attitude (Slack \& Frémont, 2005). A port challenge creates incomes from external factors such as the demand of the market, new technologies and new policies related to the environment port scheme Fig. 1.1. 


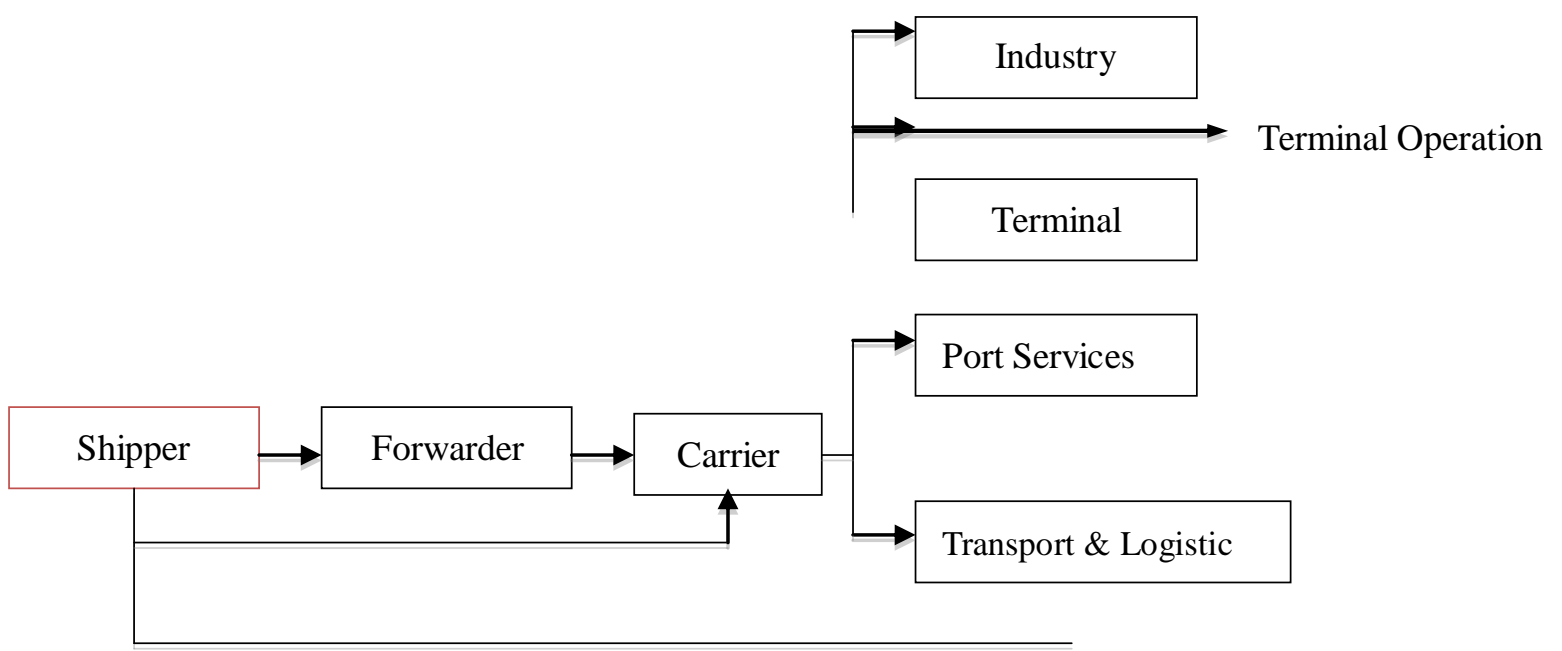

Figure 1. Port planning operation.

\subsubsection{Port Planning Process}

An element of port planning and design is necessary for any port development. A Master Plan of a port includes a layout of the port wherein land is allocated to the various uses, describes the phases needed to implement the plan, and gives an indicative implementation scheme per development phase (EMSA 2013). It incorporates preliminary designs of the major port infrastructure works - e.g.: break- water layout, dredging areas and depths, entrance channel and turning circles, plans and cross-section of quays, terminal areas, and pavements. These designs provide the basis for cost estimation, and are worked out later in a detailed design phase. A Plan simultaneously reflects the strategic objectives of government, port authority and other stakeholders, the requirements of port users and operators, and the needs of local communities (which are in turn determined by myriad global forces). The Port Authority or specialist consultant assigned to the job, depending upon the country, port, and the port management model, carries out master planning Fig. 1.2.

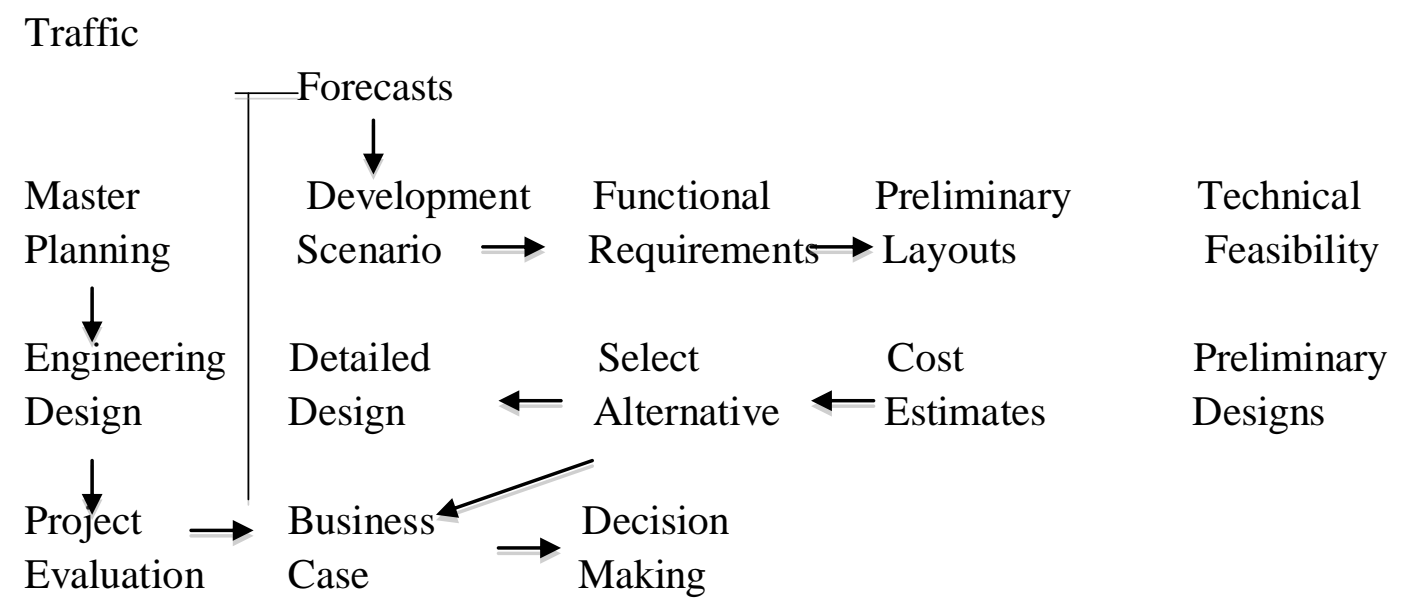

Fig. 1.2. Elements of Port Planning 


\section{Macrothink}

\section{Literature Review}

One of the few certainties in the modern world is uncertainty. The term uncertainty with reference to planning and design of port infrastructure system emphasizes that the choice of decision making must be made on the basis of incomplete knowledge about projects that do not yet physically exist, and whose projected consequences will occur-if at all-in an unknown future (Hesse, 2012). In the introduction we suggested that inadequate uncertainty consideration during port planning and design is by far the most significant reason for the 'not so successful' port development projects. We present some cases from the port sector to highlight the implications of uncertainty (Mila, S.G. (2008). Next, we depict ports as engineering systems subject to external forces. Then we go on to explore the different facets of uncertainty in general, and in the context of ports. Awareness of the prevailing trends in the port and shipping sectors is essential, since these can have direct or indirect impacts on the planning and design of ports. Therefore, we discuss some of these existing and emerging trends.

\subsection{Implications of Uncertainty for Ports}

The year 2008 saw the beginning of a global economic downturn, and international trade took a hit as credit markets froze and demand slumped. The results were visible everywhere. The number of vessels calling at Singapore, the biggest container port in the world, dropped from 1,712 to 1,466 in April 2009, compared to the year before, and throughput fell by $17.7 \%$ (Notteboom, T. (2009). The estimated number of idle container vessels at seaports worldwide soared by March 2009 to a record high of more than 450 ships with a total carrying capacity of 1.4 million TEU.

\subsubsection{Very Costly Adaptations}

The essence of a Master Plan is that you should not do today what you will have to undo tomorrow. This section gives some examples of where this is exactly what happened, sometimes at a considerable expense fig. 2.1 as operation example.

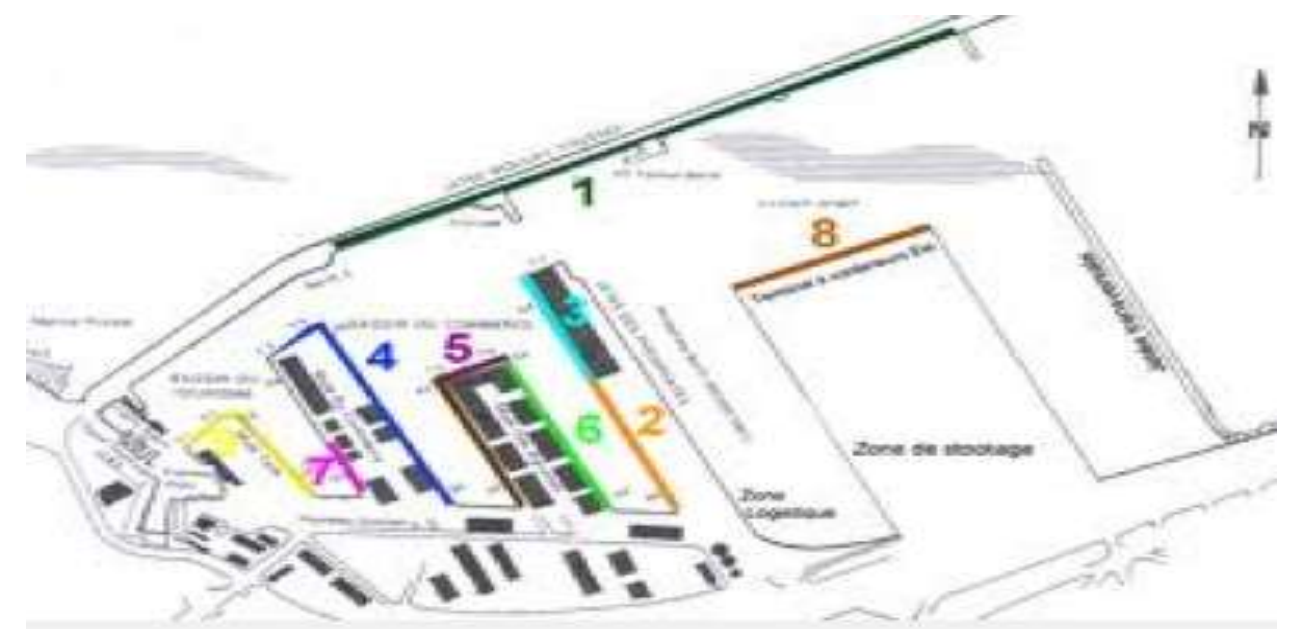

Fig. 2.1. Model Operation 
In 2001, the biggest clients of container stevedores Hanno en Uniport based at piers 5, 6, and 7 in the Waal haven were China Shipping, K-Line and Yang Ming. They expressed the intention of putting in use the new generation container ships of 5500 TEU. At that time, only third or fourth generation ships, with a draft of about $11.0 \mathrm{~m}$, were being handled in Waal-Eemhaven. The Port of Rotterdam Authority (PoRA) decided to broaden and deepen the entrance to the Waalhaven port at a cost of 13.6 million Euro in order to receive these ships.

This involved demolishing the sheds and their foundations, the existing quay walls and jetties, decontamination of the soil, and construction of a new quay wall at a distance of $78 \mathrm{~m}$ behind the original wall, thereby widening the entrance channel (Figure 2.1). In addition, the depth of new waterway was increased to NAP-15.0 m and the depth of Waalhaven basin from $13.50 \mathrm{~m}$ to $14.5 \mathrm{~m}$, giving access to vessels with a draught of up to $14.0 \mathrm{~m}$ at high tide.

\subsection{Framing the Problem}

Casa Blanca port's infrastructure constitutes the objective framework within the local economy and operation system (Hansman et al., 2005). Conventional plans of infrastructure projects usually bear all the weight and expenses of the bad side of uncertainty, without making profit from the potential of the suitable side (Ramirez, 2002). The insight of the importance of dealing with uncertainty during planning of infrastructure is on the growth.

\subsubsection{Research Design}

In the following the study present the research hypothesis the research questions, approach and contribution.

\subsubsection{Hypothesis and Questions}

Establishing ports satisfy plan and design needs and requires a new approach. Therefore, in this dissertation forward the following hypothesis:

H1: Ports efficiency integrate whole trade consistency

H2: Ports non-efficiency integrate whole trade consistency

H3: Modern port enacts low cost and high performance

H4: Modern port enacts high cost and low performance

This requires approaches for port planning and design that emphasizes the importance of flexibility and adaptability in coping with uncertainties.

Against this backdrop formulate the research question as follow:

How can efficiency port integrate the whole trade consistency?

What is one of the major challenges efficiency port?

Which plan method may change the drawbacks high-low cost level and high-low performance present structure? 
3. Methods and Framework: The Port as a Three-Layer Infra System
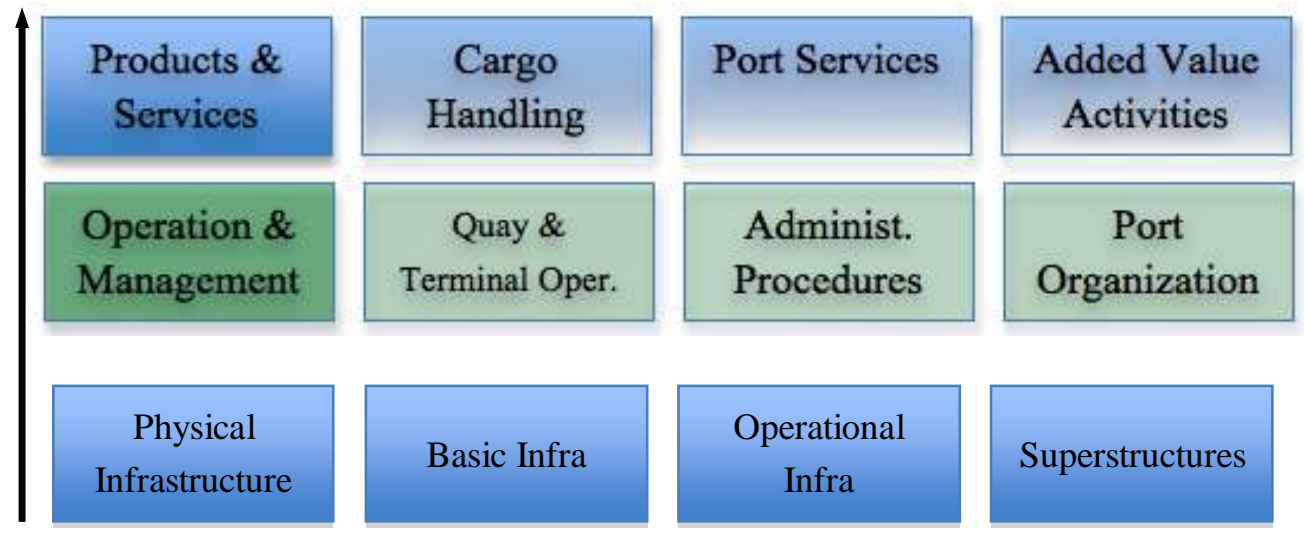

Fig. 3.1. Three Layer Infra-model of Port

We will now propose a useful framework within which to identify and incorporate flexibility in port infrastructure systems. Unlike some other systems, a port has a well-defined physical network structure, and physical goods flow through the links and nodes in the system. Some of these nodes are active where the physical good is processed, changed or converted (e.g. oil refineries or distribution centers), and the others are passive where only buffering or it is transferred to other modalities. Figure 3.1 based on Romein et al. (2003), depicts the port as a three-layer infrastructure model. The model distinguishes three generic layers: a physical infrastructure layer, an operational layer, and a services layer. The distinction among the layers is based on functionality, with the lower layers providing the conditions necessary for the existence and proper functioning of the higher layers. Each layer comprises physical, technical, operational, and institutional components, as well as actors and their interactions. The boundaries of the three layers showing various actors. A description of the three layers follows. The bottom layer covers the physical infrastructure including the basic infrastructure, superstructure, and the equipment.

Having established that we need new planning approaches that can better account for uncertainty in the Casa Blanca Port planning process, here present a framework known as Adaptive Port Planning (APP). This encompasses a new paradigm for the treatment of uncertainty. Instead of developing a static plan, this approach aims at developing plans that allow for change, learning, and adaptation over time based on new knowledge and changing circumstances.

Representatives of this paradigm are given by de (Verhetsel and Sel, 2009) and his Dynamic Strategic Planning approach with his Adaptive Policy Making approach, Notteboom (2007) with his Flexible Strategic Planning, and (Ministry of Economy, 2009) with his Adaptive Airport Strategic Planning approach. These approaches, which found their origin in airport master planning, all aim at making the plan more robust with respect to uncertainty about the future, although this capability is realized in different ways (Wilmsmeier et al. 2006). Also refer to Wijnolst, N. (2006) for a complete and concise history of adaptive policies and policymaking, beginning with the contribution of BREA (2009) who put forth an argument in 1927, that "policies be treated as experiments, with the aim of promoting continual learning 
and adaptation in response to experience over time".

In practice, port planning is primarily led by financial considerations. It involves decision-making at various stages based on a trade-offs between costs and resulting benefits. Moreover, introducing flexibility in a plan (as is the practice in APP) requires establishing its cost effectiveness based on the probability of flexibility being utilized in the future. Therefore, additional steps, which deal with the incorporation of options and an estimation of their cost effectiveness, and an overall evaluation of the alternatives defined in the first step, have been added to the framework.

\section{Contributions}

The importance of infrastructure to society is similar to the foundation of the human skeleton; it plays in the overall structuring, functioning and health of the body (Gemeente Amsterdam, 2003; 2009). Nowadays, uncertainty and flexibility considerations are required to play a large role during their planning. These subjects have only recently received attention in the port sector due to developments such as the downward turn in throughput due to the financial crisis, and technological breakthroughs such as Maersk's Triple-E container mega vessels and APM Terminal's FASTNET cranes. Though sporadic research is being carried out, resulting in innovations in products and processes, the issues why, how and where with respect to uncertainty and flexibility have not been dealt with in an integrated manner. As a result, concepts and methodology for port planners in times of uncertainty, is missing.

Therefore, this dissertation addresses the highly topical issue of infrastructure planning under uncertainty. It proposes an adaptive approach to planning or APP that guides a planner to first identify and then systematically deal with uncertainties that appears over the lifetime of a project, and results in Plans and infrastructure design that can better stand the vagaries of the future. This research frames the issues of flexibility and adaptability, gives a better understanding of how these concepts can be integrated into port planning, and suggests how the added value of flexibility can be included during port evaluation to support the research hypothesis.

\section{Conclusion \& Limitation}

As an essential the innovation in different areas became to set new ideas, as Casablanca port request to implement an APP, which is a platform planning. The study to follow an APP framework structure will create a flexible planned innovation.

An innovation in logistic management request local government support playing the facilitator role, otherwise the innovation may not blowup, an investment will be required according of the project scale and the authority.

Today's economic environmental cannot be handled new challenges just with technology at hand, the competition request innovation, so need to innovate. Innovation is more than new technology, it involves how business processes are integrated and managed.

Casablanca port infrastructure, as TEU require important series of innovations aimed at improving productivity, which is related to the implementation of APP innovation. 
At the global situation may an international port to maximize productivity and begin investment process.

\subsection{Some Limitations}

Planning is formulating a strategy to complete a goal. Simply put, planning is deciding in advance what to do, how to do it, and who is to do it (Koontz and O' Donnell, 1972). Planning can be aimed at annual budget allowance or training of people (short-term planning), investment (middle-term planning), spatial planning is a reform (long-term planning). In this dissertation, the focus will be on middle to long-term planning.

The problems related to port planning in Casa Blanca Port could be because the absence of a central planning organization, or the constraints embodied in the institutional framework of the organization (Frankel, 1987). The biggest challenge for port planners happens from exogenous features such as uncertainty in market demand, new technology, and new policies related to environmental, safety, and security issues. The difficulty of reaching a common understanding of goals and expectations among the numerous stakeholders and disciplines involved in the planning and design of ports adds to this challenge.

\section{References}

Blyde, J., \& Molina, D. (2013) Logistics Infrastructure and the International Location of Fragmented Production, MPRA Paper No. 45749.

BREA (2009). Economic Contribution of Cruise Tourism to the Destination Economies: A survey-based analysis of the impacts of passenger, crew, and cruise line spending. Volume II Destination Reports. Prepared for Florida-Caribbean Cruise Association October 2009.

EMSA, E. M. S. A. (2013), Port Waste Reception Facilities. [Online] Available:http://emsa.europa.eu/implementation-tasks/environment/port-waste-reception-facil ities.html

Gemeente Amsterdam. (2003). Bedrijfslocaties in Amsterdam 2003. Ontwikkelingsbedrijf Amsterdam, Gemeentelijk Havenbedrijf, Dienst Economische Zaken and Dienst Ruimtelijke Ordening, Amsterdam.

Gemeente Amsterdam. (2009). Bedrijfslocaties inAmsterdam2003.Ontwikkelingsbedrijf Amsterdam, Gemeentelijk Havenbedrijf, Dienst Economische Zaken \& Amsterdam.

Haddad, E., Hewings, G., Perobelli, F., \& Dos Santos, R. (2010). Regional Effects of Port Infrastructure: A Spatial CGE Application to Brazil. International Regional Science Review, $33,239-263$

Jacobs, W., Ducruet, C., \& de Langen, P. W. (2010). Integrating World Cities into Production Networks: The Case of Port Cities. Global Networks, 10(1), 92-113.

Marshall, R. (2001). Modern ports and historic cities: Genoa and Las Palmas de Gran Canaria. Waterfronts in Post-Industrial Cities (edited by Richard Marshall), London: Spon Press.

Merk, O., \& Hesse, M. (2012). The Competitiveness of Global Port-Cities: The case of 
Hamburg, OECD Regional Development Working Paper, Paris.

Mila, S. G. (2008). Case-study Barcelona, presentation at the ESPO-EFIP International Workshop on $\square$ Ports - Facilitators in the Logistics Chain', Strasbourg, 11 March 2008.

Ministry of Economy. (2009). Economische visie op de langetermijnontwikkeling van Mainport Rotterdam; Op weg naar een Mainport Netwerk Nederland, together with Ministry of Traffic and Infrastructure and Ministry of Housing, Spatial Planning and the Environment, The Hague.

Muriello, M., \& Jiji. D. (2004). The value pricing toll program at the port authority of New York \& New Jersey: revenue for transportation investment and incentives for traffic management, unpublished paper.

Notteboom, T. (2004). Container Shipping and Ports: An Overview. The Review of Network Economics, 3(2), 86-106.

Notteboom, T. (2009). The relationship between seaports and the intermodal hinterland in light of global supply chains: European challenges, in: OECD/ITF (ed.), $\square$ Port Competition and Hinterland Connections', Round Table no. 143, OECD - International Transport Forum (ITF): Paris, ISBN 978- 92-821-0224-4, p. 25-75.

Notteboom, T. (2009b). Complementarity and substitutability among adjacent gateway ports. Environment and Planning A, 41(3), 743-762.

Pallis, A. Notteboom, T., \& De Langen, P. (2008). Concession Agreements and Market Entry in the Container Terminal Industry. Maritime Economics \& Logistics, 10, 209-228

Romein, A., Trip, J., \& De Vries, J. (2003). The Multi-scalar complexity of infrastructure planning: evidence from the Dutch-Flemish megacorridor. Journal of Transport Geography, $11,205-213$.

S. Rick Fernandez. (2013). It takes two to tango: Commercial Relation Beyond of Bilateral Agreement, China and Colombia to sign a Free Trade Agreement. American Journal of Business and Management, 2(4), 275-295. http://dx.doi.org/10.11634/216796061302426

Slack, B., \& Frémont, A. (2005). Transformation of port terminal operations: From the local to the global. Transport Reviews, 25, 117-130.

Van der Horst, M., \& De Langen, P. (2008). Coordination in Hinterland Transport Chains: A Major Challenge for the Seaport Community. Maritime Economics \& Logistics, 10, 108-129.

Verhetsel, A., \& Sel, S. (2009). World Maritime Cities: from Which Cities Do Container Shipping Companies Make Decisions. Transport Policy, 16(5), 240-250.

Wang J. J., Koi-Yu-Ng A., \& Olivier D. (2004). Port governance in China: A review of policies in an era of internationalizing port management practices. Transport Policy, 11, 237-250.

Wijnolst, N. (2006). Dynamic European Maritime Clusters, Amsterdam, IOS Press BV. 


\section{Macrothink}

Business Management and Strategy

ISSN 2157-6068

2014, Vol. 5, No. 2

Wilmsmeier, G., Hoffmann, J., \& Sanchez, R. (2006). The impact of port characteristics on international maritime transport costs. Research in Transport Economics, 16, 117-140.

Yang, Y., \& Shen, K. (2013). Comparison of the operating performance of automated and traditional container terminals. International Journal of Logistics Research, 16(2), 158-173.

\section{Copyright Disclaimer}

Copyright for this article is retained by the author(s), with first publication rights granted to the journal.

This is an open-access article distributed under the terms and conditions of the Creative Commons Attribution license (http://creativecommons.org/licenses/by/3.0/). 